\title{
Morphological, Liquid Crystal and Optical Band Energy Properties of Polyphosphates
}

\author{
Evon Akram ${ }^{1}$, Gamal A. El-Hiti ${ }^{2 *}$, Dina S. Ahmed ${ }^{3}$, Alaa Adnan Rashad ${ }^{1}$, \\ Wedad H. Al Dahhan ${ }^{1}$ and Emad Yousif ${ }^{1 *}$ \\ ${ }^{1}$ Department of Chemistry, College of Science, Al-Nahrain University, Baghdad-Iraq. \\ ${ }^{2}$ Department of Optometry, College of Applied Medical Sciences, King Saud University, \\ P.O. Box 10219, Riyadh 11433, Saudi Arabia. \\ ${ }^{3}$ Department of Medical Instrumentation Engineering, Al-Mansour University College,Baghdad-Iraq. \\ "Corresponding authors: emadayousif@gmail.com; gelhiti@ksu.edu.sa.
}

\begin{abstract}
New metallic liquid crystalline polyphosphates showed thermotropic nematic liquid crystal phases (2.13-2.24 eV). The surface morphology of polyphosphates was examined by the scanning electron microscope and showed rough surface and micro pore structure which an indication of the presence of several crystalline domains. [DOI: 10.22401/ANJS.22.2.03]
\end{abstract}

Keywords: polyphosphates; polymer liquid crystal; morphology; energy gap.

\section{Introduction}

Liquid crystalline polymers (LCPs) have attract the attention worldwide due to their interesting properties [1,2]. They have a high chemical resistance, stiffness and strength. In addition, they have a good dimensional stability and low linear thermal expansion coefficient [3-6]. LCPs are of two types that known as side-chain and main-chain based on the location in which mesogenic moieties attached to the backbone of the polymer. The crosslinked LCPs have large spontaneous de-formations [7] in response to changes in temperature $[8,9]$, electric and magnetic fields [10] and light illuminations [11,12], for example. The spontaneous deformation is related to LCPs liquid crystallinity [13]. Materials that have polymeric side-backbone provides the anisotropy properties to liquid crystalline mesogens. While, rigid structures were produced for materials that have polymeric main-chain backbone and leads to high strength and melting temperature. Two common types of LCPs are known as lyotropic and thermotropic LCPs [14,15]. Lyotropic LCPs have liquid crystalline structures in solution and can be fabricated as films or fibers [14]. Thermotropic LCPs have liquid crystalline structures and can be produced upon heating [15] and can be made as threedimensional structures using injection molding, for example [16]. The modification of the structures and properties of LCPs is of great interest [17-19]. LCPs have high transition temperatures in most cases [20-25]. There are several processes to reduce the tarnation energy by the incorporation of flexible spacers [20], frustrated chain packing [21], nonlinear links [22] and substitution of mesogenic segment [23]. Polymer dispersed liquid crystal materials can be used in building partitions, privacy windows, projection displays, for example [26,27]. Polymer stabilized liquid crystal materials have a uniform oriented polymer networks within the LC matrix [28,29]. The current work investigates the use of new metallic liquid crystal polymers sensing and liquid crystal orientation that is extremely sensitive to the morphology, physical and chemical properties of the surface.

\section{Experimental}

\subsection{Polyphosphates 1-3}

Polyphosphates 1-3 Fig.(1) were obtained as previously reported and their structures were confirmed $[30,31]$. 


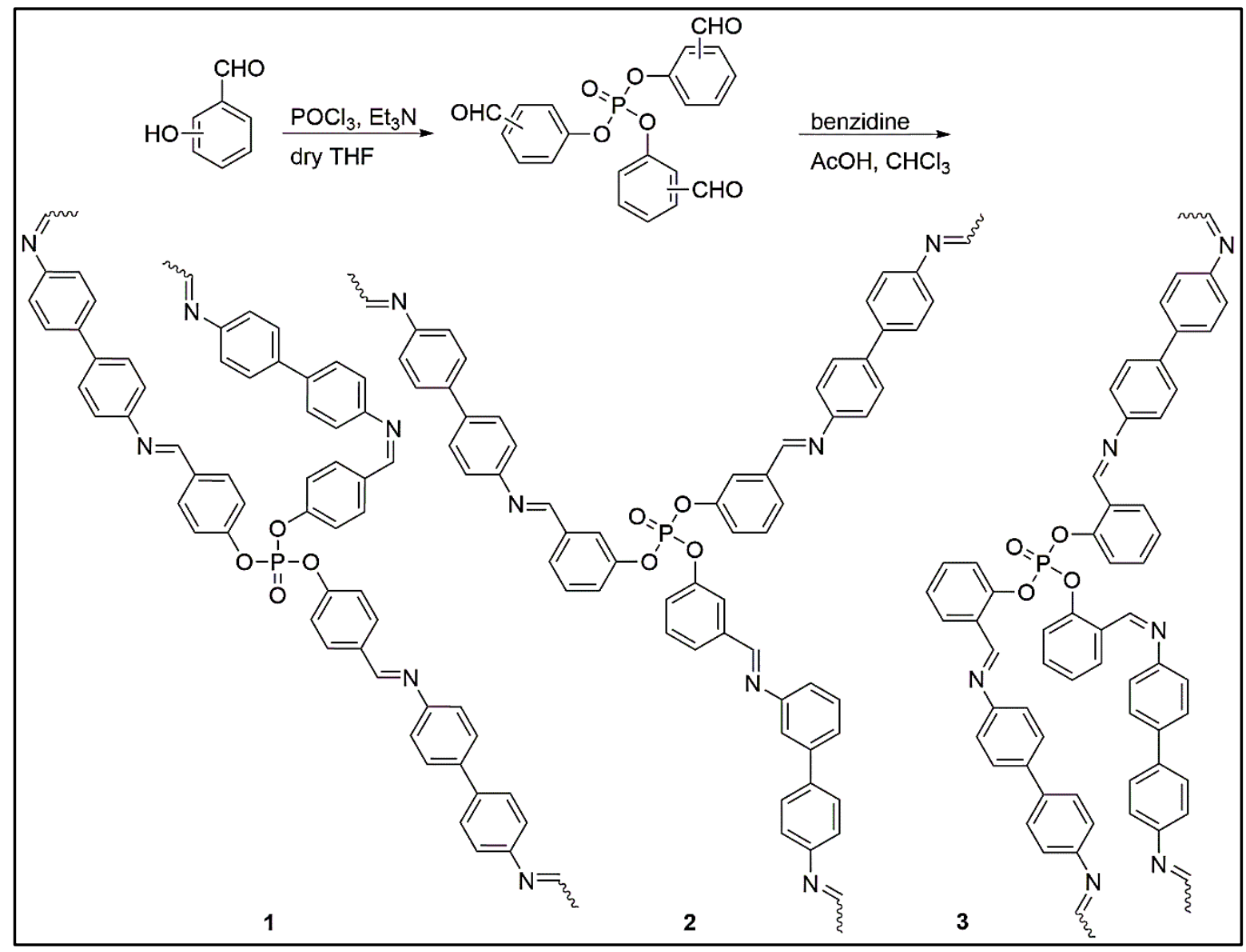

Fig. (1): Polyphosphates 1-3.

\subsection{Spectral analysis}

The reflection spectra and band energy for polyphosphate samples ( $c a .500 \mu \mathrm{m}$ diameter) were obtained using an unpolarized deuteriumhalogen light source (Avantes AvaLight-DH$\mathrm{S}$, Apeldoorn the Netherlands). The scanning electron microscope (SEM) images (accelerating voltage $=15 \mathrm{Kv}$ ) were recorded on Inspect S50 microscope (FEI Company, Czechia, Czech Republic).

\section{Results and Discussion}

\subsection{Liquid crystalline properties}

The hot-stage optical polarized light microscope was used to observe the mesophase of thermotropic liquid crystal polyphosphate 3. Fig.(2) shows the crystalline texture of the mesogen in which the phase transition occurred and a nematic texture character was observed at 290 and $350^{\circ} \mathrm{C}$. The color of polyphosphate 3 was deep brown, the transition phase from solid to nematic phase $(\mathrm{C}-\mathrm{N})$ took place at $290^{\circ} \mathrm{C}$, the transition phase from nematic to isotropic phase $(\mathrm{N}-\mathrm{I})$ took place at $480^{\circ} \mathrm{C}$ and the thermal stability of the nematic phase $(\Delta \mathrm{T})$ took place at $190^{\circ} \mathrm{C}$. 

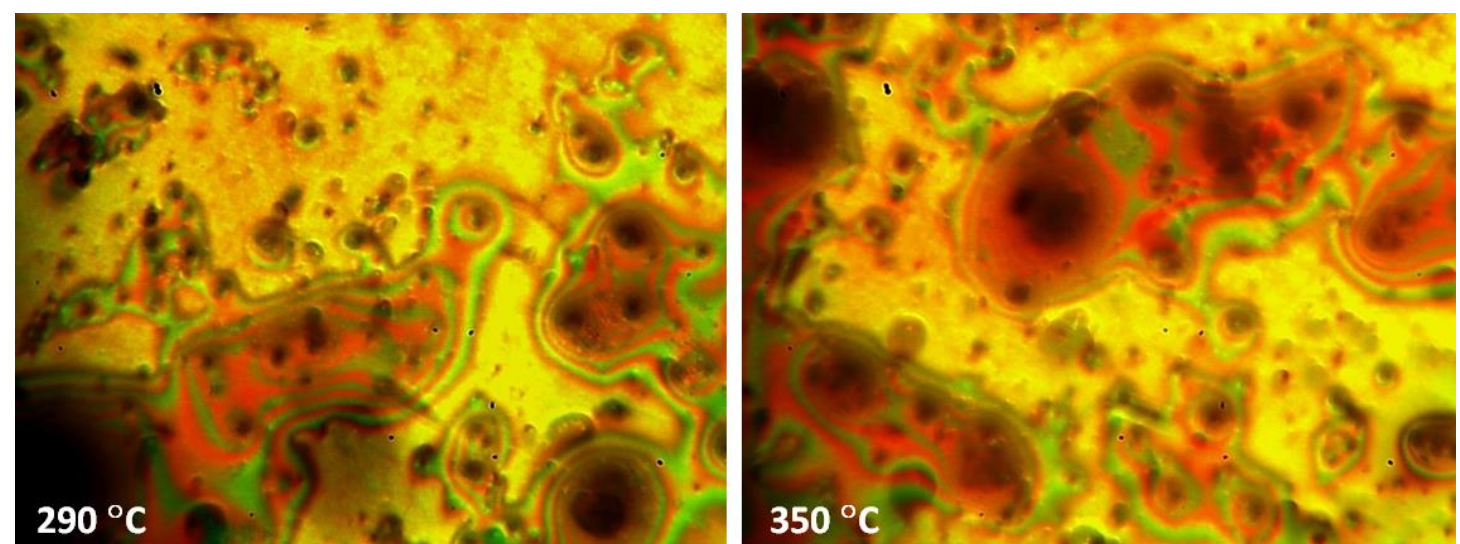

Fig (2): Crystalline texture of the mesogen polyphosphates 3 at 290 and $350{ }^{\circ} \mathrm{C}(20 x)$.

\subsection{Scanning electron microscopy (SEM)}

The surface morphology of 1-3 was examined by the SEM at accelerating voltage of $15 \mathrm{kV}$. The SEM images are shown in Figs.(3-5).
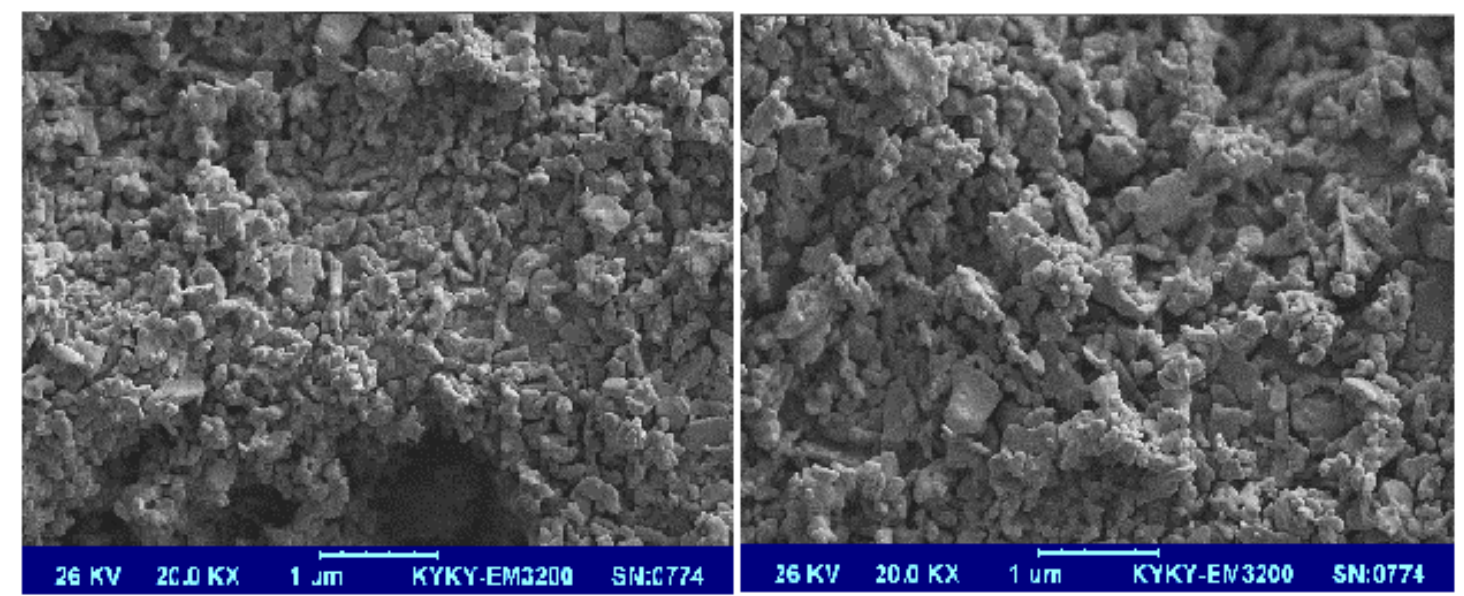

Fig.(3): SEM images of polyphosphate 1.

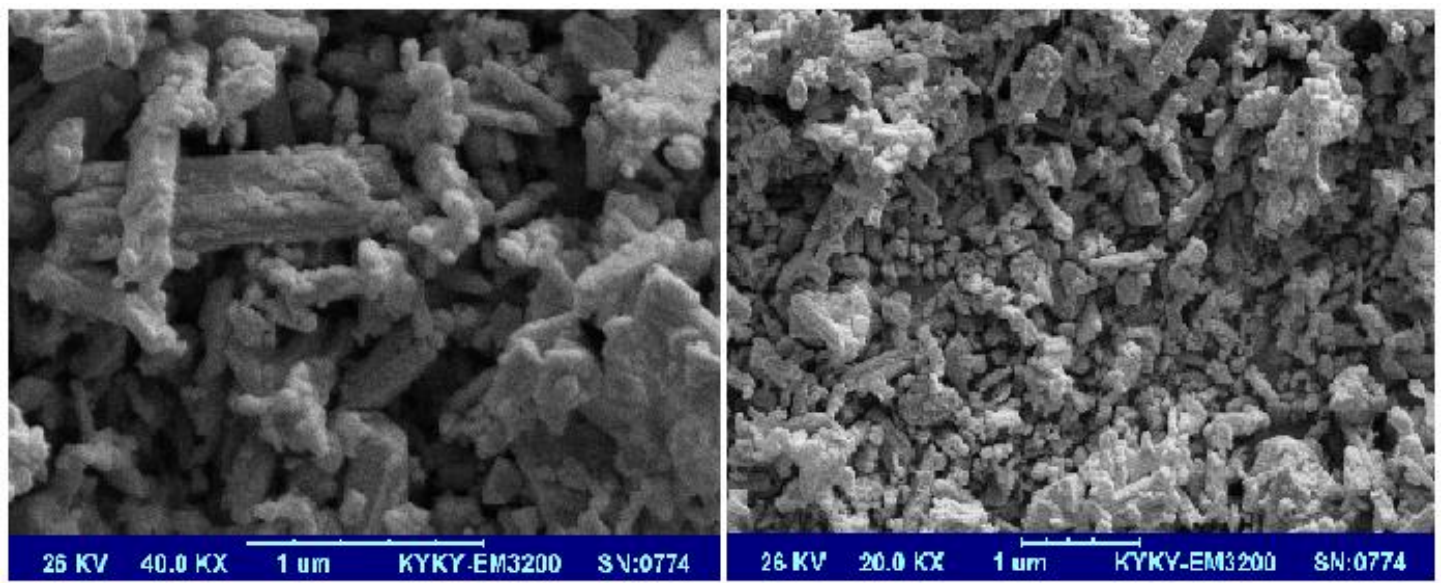

Fig.(4): SEM images of polyphosphate 2. 


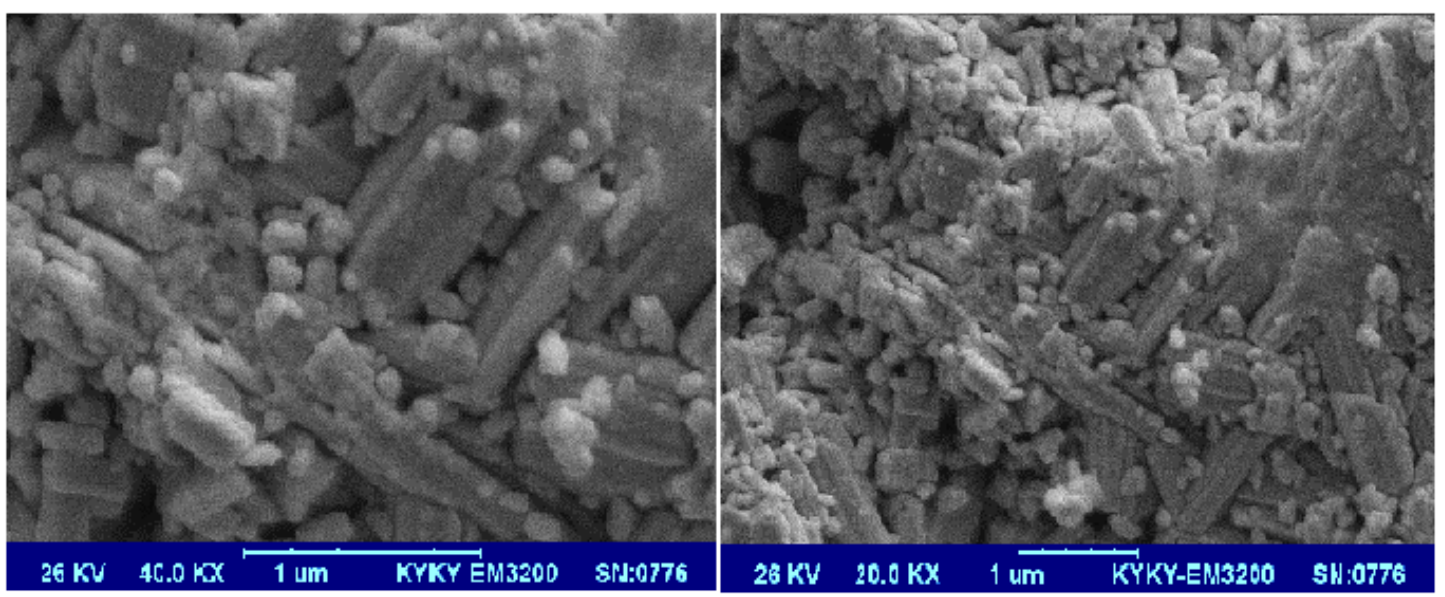

Fig.(5): SEM images of polyphosphate 3.

The SEM images of 1-3 showed a porous amorphous structure as a result of the azomethane $(-\mathrm{CH}=\mathrm{N}-)$ linked networks (Figs. (6-8)). Polyphosphates 1-3 have nanosized particles in most cases and their dimensions were $c a$. 40-165, 28-806 and 30-598 nm for 1, 2 and 3, respectively. The SEM indicated that the agglomerated particles of polyphosphates 1 and 2 arranged side by side to produce a topographical microporous structures forming clusters as a result of the high surface energy Figs.(6) and (7). While, the SEM images of 3 revealed an irregular morphology with rod-like mesogens Fig. (8) which can be used as building blocks to construct liquid crystal with optical properties [32].

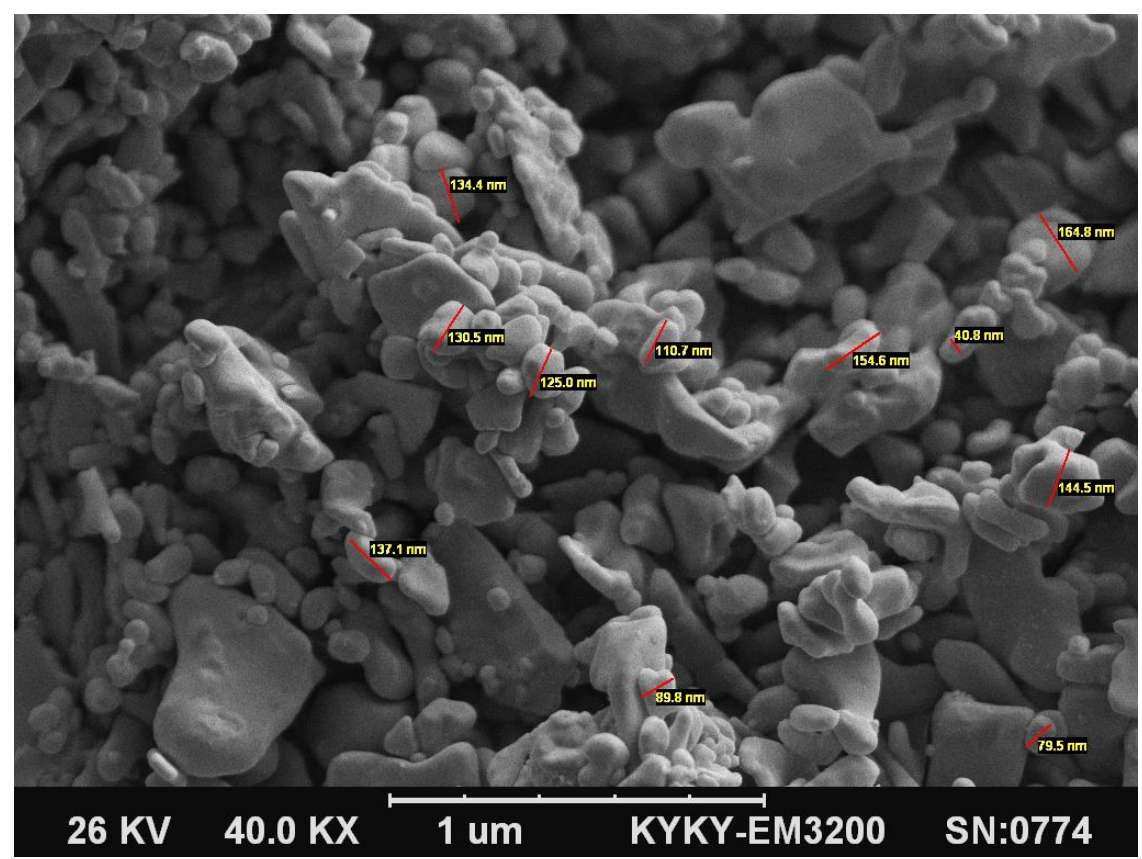

Fig.(6): SEM images with dimension range of polyphosphate 1. 


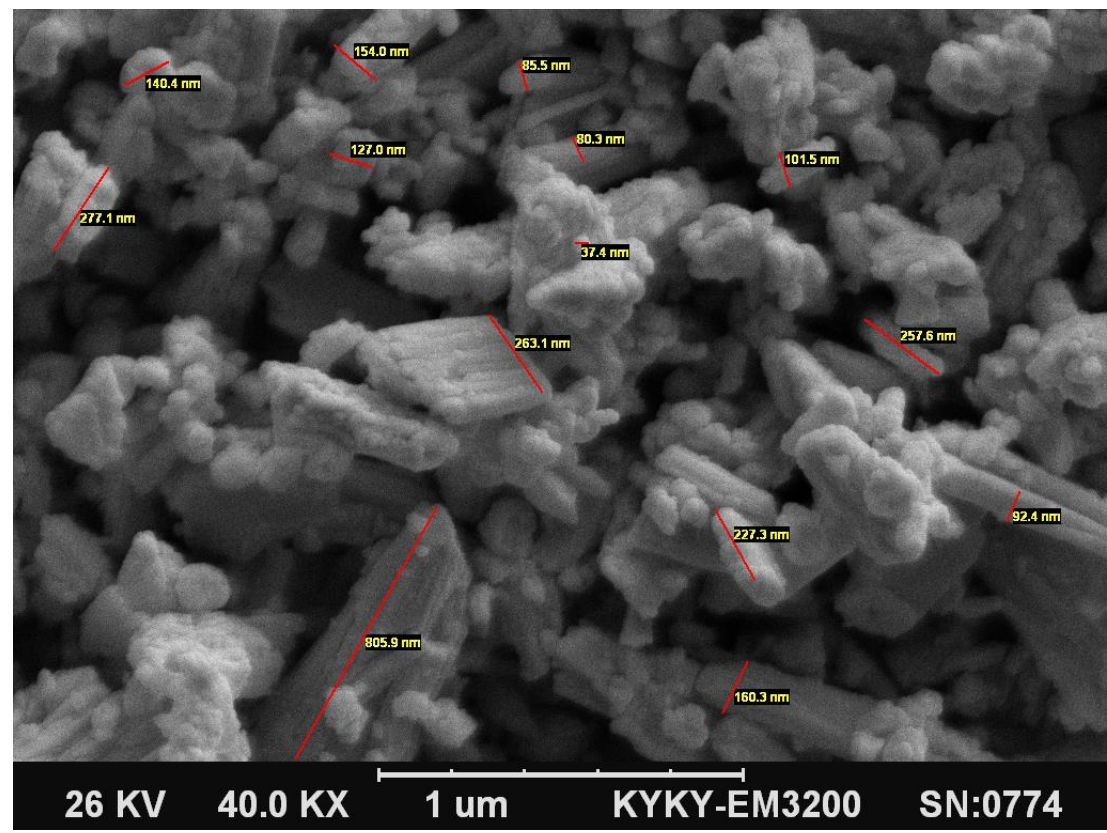

Fig.(7): SEM images with dimension range of polyphosphate 2.

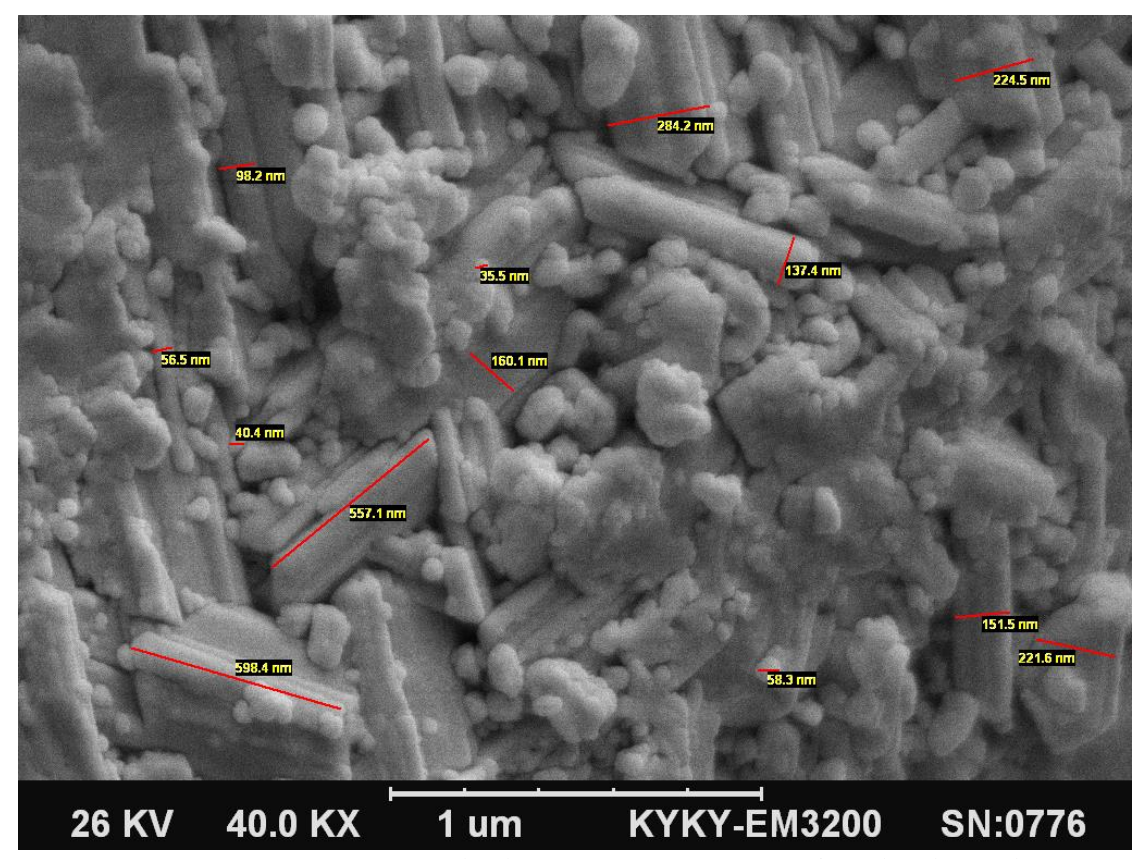

Fig.(8): SEM images with dimension range of polyphosphate 3.

\subsection{Photonic properties}

The absorption band edge can be used as a useful tool to investigate optically the induced transition. Photons with energy higher than the band gap energy (Eg) should be absorbed [33].

In crystalline and non-crystalline materials, the electronic transitions between the valence and conduction bands start at the absorption edge. The absorption edge or $\mathrm{Eg}$ is the minimum energy difference between the lowest minimum of the conduction band and the highest maximum of the valence band. The changes in the optical absorption spectra of 1-3 with a high energy proton beam
(2.13-2.24 eV) are shown in Figs.(9-11). From the band energy $(\mathrm{Eg})$, it has been observed the polyphosphate 3 was the best in terms of semiconductor properties which is a determining factor for the structural stability [34]. 


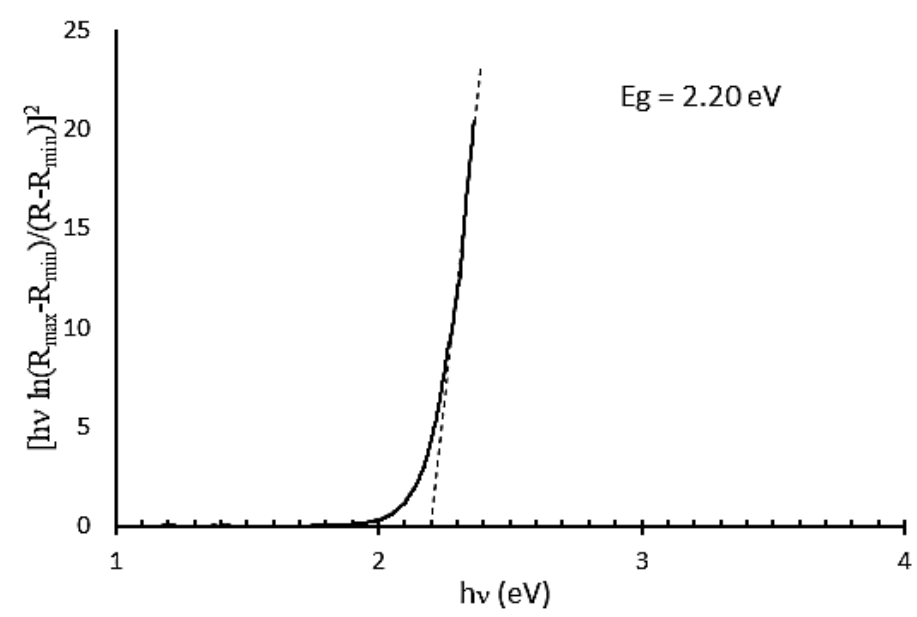

Fig.(9): Plot of [hvln(Rmax-Rmin)/(R-Rmin) $]^{2} v s . h v$ for polyphosphate 1.

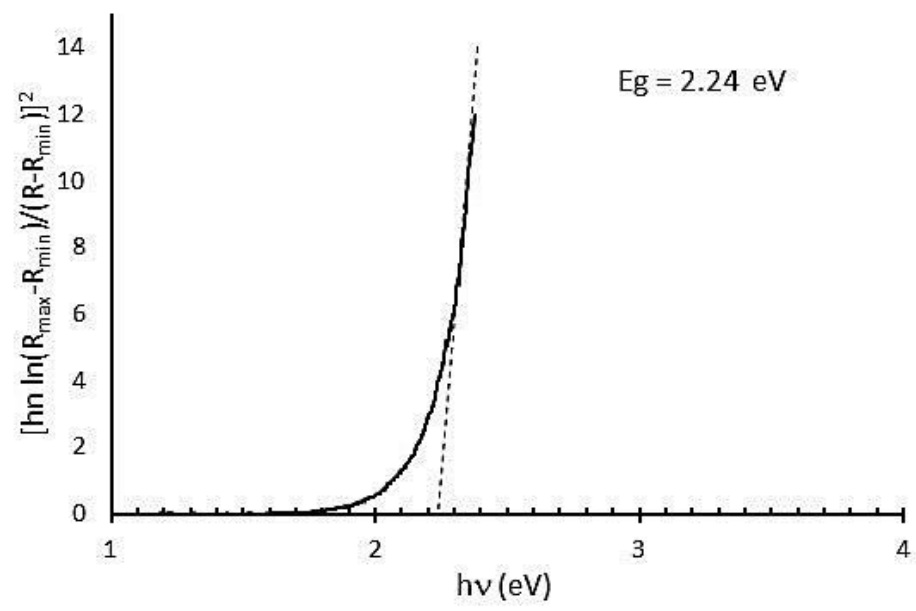

Fig.(10): Plot of [hvln(Rmax-Rmin)/(R-Rmin) $]^{2} v s . h v$ for polyphosphate 2.

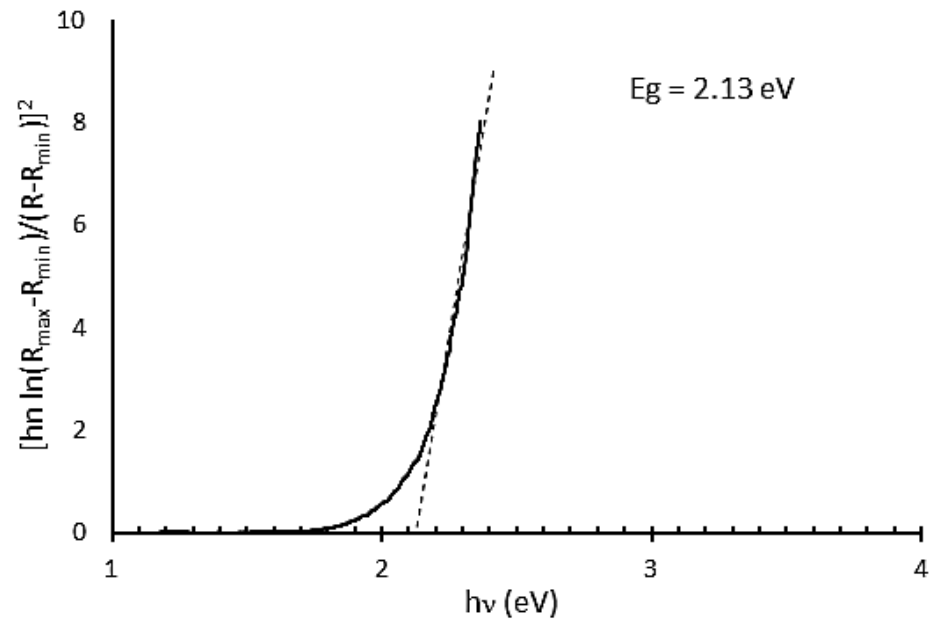

Fig.(11): Plot of [hvln(Rmax-Rmin)/(R-Rmin) $]^{2} v s$. hv for polyphosphate 3.

The polarizing force of the $-\mathrm{CH}=\mathrm{N}$ bonds and the resonance effect within the aromatic rings can have an effect on the formation of liquid crystal phases and their stability. Polyphosphate 3 gave a liquid crystal phases possibly as a result of the strong polarization effect of the $-\mathrm{CH}=\mathrm{N}$ - bonds of the ortho-substitution compared with the meta- (2) and the para-substitution (1). Polyphosphate 3 showed liquid crystalline phase properties at 50-400 and 440-460 $\mathrm{nm}$ regions with a light reflectance percentage of 18 , and $26 \%$, respectively due to the high the irregularity of the internal arrangement of 3 compared to 1 and 2 Fig.(12). 


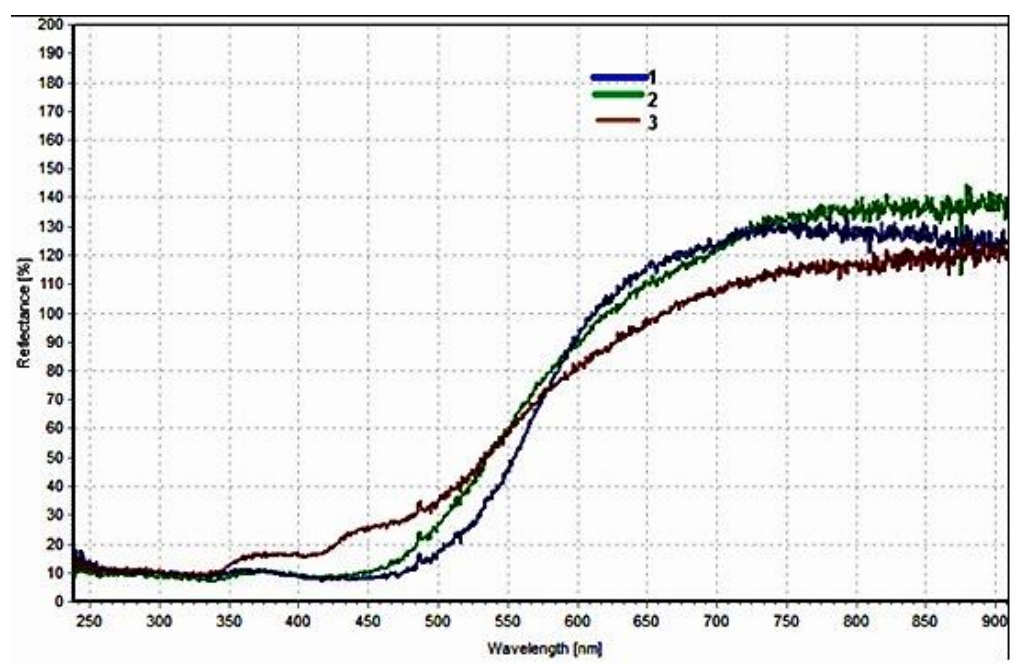

Fig.(12): Reflectance of polyphosphates 1-3.

\section{Conclusion}

New metallic crystalline liquid polyphosphates were developed and could be used to adsorb gas molecule efficiently in range of $2.13-2.24 \mathrm{eV}$. The ortho-substituted polyphosphate 3 was found to be the most efficient liquid crystal.

\section{Acknowledgments}

This work was supported by Al-Nahrain University.

\section{References}

[1] Broer D., Crawford G.P., Zumer S., CrossLinked Liquid Crystalline Systems: From Rigid Polymer Networks to Elastomers. CRC Press, 2011.

[2] Li Q., Nanoscience with Liquid Crystals. Springer International PU, 2016.

[3] Chen B.-K., Tsay S.-Y., Chen J.-Y., Synthesis and properties of liquid crystalline polymers with low $T_{\mathrm{m}}$ and broad mesophase temperature ranges. Polymer, 46, 8624-8633, 2005.

[4] Williams D.J., Applications for thermotropic liquid crystal polymer blends. Adv. Polym. Technol., 10, 173-184, 1990.

[5] Zhu Z., Zhi J., Liu A., Cui J., Tang H., Qiao W., Wan X., Zhou Q., Synthesis and characterization of a thermotropic liquid- crystalline poly[2,5- bis (4'alkoxycarbonylphenyl) styrene]. J. Polym. Sci.: Polym. Chem., 45, 830-847, 2007.

[6] Kim J.Y., Carbon nanotube-reinforced thermotropic liquid crystal polymer
Nanocomposites. Materials, 2, 1955-1974, 2009.

[7] de Gennes P.G., Prost J.P., The Physics of Liquid Crystals. Oxford University Press, 1994.

[8] Buguin A., Li M.-H., Silberzan P., Ladoux B., Keller P., Micro-actuators: when artificial muscles made of nematic liquid crystal elastomers meet soft lithography. J. Am. Chem. Soc., 128, 1088-1089, 2006.

[9] Burke K.A., Mather P.T., Soft shape memory in main-chain liquid crystalline elastomers. J. Mater. Chem., 20, 34493457, 2010.

[10] Yusuf Y., Huh J.H., Cladis P.E., Brand H.R., Finkelmann H., Kai S., Low voltagedriven electromechanical effects of swollen liquid-crystal elastomers, Phys. Rev. E Stat. Nonlin. Soft Matter. Phys., 71, 061702, 2005.

[11] Hogan P.M., Tajbakhsh A.R., Terentjev E.M., UV manipulation of order and macroscopic shape in nematic elastomers. Phys. Rev. E Stat. Nonlin. Soft Matter. Phys., 65, 041720, 2002.

[12] Harris K.D., Cuypers R., Scheibe P., van Oosten C.L., Bastiaansen C. W.M., Lub J., Broer D.J., Large amplitude light-induced motion in high elastic modulus polymer actuators. J. Mater. Chem., 15, 5043-5048, 2005.

[13] Khaligh H.H., Liew K., Han Y., Abukhdeir N.M., Goldthorpe I.A., Silver nanowire transparent electrodes for liquid crystal-based smart windows. Sol. Energy Mater. Sol. Cells, 132, 337-341, 2015 
[14] Collings P.J., Liquid Crystals: Nature's Delicate Phase of Matter. Princeton University Press, 2002

[15] Pavel D., Hibbs D., Shanks R., Review of main chain liquid crystalline polymers. Adv. Res. Polym. Sci., 65-84, 2006.

[16] Yoon H.N., Charbonneau L.F., Calundann G.W., Synthesis, processing sand properties of thermotropic liquid- crystal polymers. Adv. Mater., 4, 206-214, 1992.

[17] Chavan N.N., Mulani K.B., Thermotropic Liquid Crystalline Polyesters. Lambert Academic Publishing Co., Verlag, Germany, 2012.

[18] Gary G.W., Liquid Crystallinity in Polymers: Principle and Fundamental Properties. VCH Verlagsgesellschaft, Weinheim, 1991.

[19] Ganicz T., Stańczyk W., Side-chain liquid crystal polymers (SCLCP): methods and materials. An overview. Materials, 2, 95-128, 2009.

[20] Zheng R.Q., Chen E.-Q., Cheng S.Z.D., Xie F., Yan D., He T., Percec V., Chu P., Ungar G., Phase identification in a series of liquid crystalline TPP polyethers and copolyethers having highly ordered mesophase structures. 7. Phase structures in a series of copolyethers containing odd and even numbers of methylene units of different compositions. Macromolecules, 32, 6981-6988, 1999.

[21] Tokita M., Osada K., Thermotropic liquid crystal of main-chain polyester having a mesogenic 4,4'-bibenzoate unit. 11. Study on smectic liquid crystalline glass. Polym. J., 30, 589-595, 1998.

[22] Chang H.-S., Wu T.-Y., Chen Y., Synthesis and properties of TLCPs with 2,6-naphthalene-based mesogen, polymethylene spacer and non-linear 4,4'-thiodiphenyl links. J. Appl. Polym. Sci., 83, 1536-1546, 2002.

[23] Ha H., Bhowmik P.K., Wholly aromatic liquid-crystalline polyesters. Prog. Polym. Sci., 22, 1431-1502, 1997.

[24] van Oosten C.L., Bastiaansen C.W.M., Broer D.J., Printed artificial cilia from liquid-crystal network actuators modularly driven by light. Nat. Mater., 8, 677-682, 2009.
[25] De Haan L.T., Gimenez-Pinto V., Konya A., Nguyen T.-S., Verjans J. M.N., Sánchez-Somolinos C., Selinger J.V., Selinger R.L.B., Broer D.J., Schenning A.P.H.J., Accordion-like actuators of multiple $3 \mathrm{~d}$ patterned liquid crystal polymer films. Adv. Funct. Mater., 24, 1251-1258, 2014.

[26] Khaligh H.H., Liew K., Han Y., Abukhdeir N.M., Goldthorpe I.A., Silver nanowire transparent electrodes for liquid crystal-based smart windows. Sol. Energy Mater. Sol. Cells, 132, 337-341, 2015.

[27] Chen M., Hu W., Liang X., Zhang H., Zhang C., Song P., Zhang L., Li F., Chen F., Yang H., The regulation of polymer structures and electro-optical properties of epoxy-mercaptan-based phase separated liquid crystals/polymer composites. Polymer, 127, 1-7, 2017.

[28] Ahmad F., Jamil M., Jeon Y.J., Reverse mode polymer stabilized cholesteric texture (PSCT) light shutter display - A short review. J. Mol. Liq., 233, 187-196, 2017.

[29] Moheghi A., Nemati H., Li Y., Li Q., Yang D.-K., Bistable salt doped cholesteric liquid crystals light shutter. Opt. Mater., 52, 219-223, 2016.

[30] Ahmed D.S., El-Hiti G.A., Yousif E., Hameed A.S., Abdalla M., New ecofriendly phosphorus organic polymers as gas storage media. Polymers, 9, 336, 2017.

[31] Ahmed D.S., El-Hiti G.A., Yousif E., Hameed A.S., Polyphosphates as inhibitors for poly(vinyl chloride) photodegradation. Molecules, 22, 1849, 2017.

[32] Fu M., Zhang Z., Highly tunable liquid crystalline assemblies of superparamagnetic rod-like attapulgite@Fe3O4 nanocomposite. Mater. Lett., 226, 43-46, 2018.

[33] Urbach F., The long-wavelength edge of photographic sensitivity and of the electronic absorption of solids. Phys. Rev., 92, 1324, 1953.

[34] Ren L., Cheng L., Feng Y., Wang X., Geometric and electronic structures of $(\mathrm{BeO})(\mathrm{N})(\mathrm{N}=2-12,16,20$, and 24$)$ : rings, double rings, and cages. J. Chem. Phys., 137, 014309, 2012. 